\title{
Analisis Miskonsepsi Peserta Didik Sekolah Menengah Atas pada materi Fisika
}

\section{OJS}

\section{Rohman Entino*, Eko Hariyono, Nurita Apridiana Lestari}

Program Studi Pendidikan Fisika, Fakultas Matematika dan ilmu Pengetahuan Alam, Universitas Negeri Surabaya

*Email: rohmanentino16030184077@mhs.unesa.ac.id

DOI: https://doi.org/10.33369/pendipa.6.1.177-182

\begin{abstract}
Students which experienced misconception during physical science learning, thus researcher do analytic descriptive research with sample subject, and also using diagnostic test with Certainty of Response Index (CRI) scale which aims to analyze students understanding levels about physics. the results show the percentage of understanding the concept is 29,72 with low category, and 18,32 for unsure of understanding the concept, 28,06 for misconception with low rate category, and 18,32 for those with no understanding of the concept with low rate. Hereby factors that cause misconception in class X SMAN 1 DRIYOREJO include the ability of students, the low interest in learning of students, and how to educate in class.
\end{abstract}

Keywords: Misconception, Certainty of Response Index (CRI), Physics, Understanding the concept.

\begin{abstract}
ABSTRAK
Berawal dari peserta didik yang mengalami miskonsepsi pada saat pembelajaran fisika, maka peneliti melakukan penelitian deskriptif analisis dengan subjek sampel dan menggunakan tes diagnostik dengan skala (CRI) yang bertujuan menganalisis tingkat pemahaman peserta didik pada materi fisika. Hasil dari penelitian memberikan hasil persentase pemahaman konsep sebesar 29,72\% dengan kategori persentase rendah, dan 18,32\% untuk memahami konsep tetapi tidak yakin dengan kategori rendah, kemudian persentase miskonsepsi sebesar 28,06\% dengan kategori persentase rendah, dan 23,89\% untuk tidak paham konsep dengan kategori persentase yang rendah. faktor - faktor yang menyebabkan miskonsepsi peserta didik kelas X SMAN 1 DRIYOREJO antara lain kemaampuan pesertaa didik, rendahnya minat belajar peserta didik, dan cara mengajar dalam kelas.
\end{abstract}

Kata kunci: Miskonsepi, Kepastian Indeks, Fisika, Pemahaman Konsep.

\section{PENDAHULUAN}

Fisika merupakan suatu ilmu yang mengkaji sebuah fenomena alam beserta gejalagejala yang terjadi di sekitar yang melalui serangkaian proses ilmiah dan hasilnya diakui sebagai produk ilmiah yang terdiri atas konsep, prinsip, dan teori. Ilmu Fisika sangat identik dengan fenomena alam, jadi saat mempelajari ilmu fisikaa harus kemampuan dalam memahami gagasan dari suatu materi fisika. Setiap konsep tidak bias berdiri sendiri melainkan ada hubungan antara konsep yang satu dengan konsep yang lain. Fisika penting diajarkan serta diaplikasikan dalam sekolah karena memberikan bekal ilmu pengetahuan terhadap peserta didik dan menjadikan wadah sebagai tumbuhnya kemampuan/keterampilan bekerja ilmiah guna untuk memecahkan masalah 
yang ada didalam kehidupan sehari-hari (Giancoli, 2001).

Menurut Mosik (2010) sebelum mempelajari fisika, peserta didik datang kelas tidak dalam keadaan kepala kosong. Struktur kogniitif peserta didik telah terbentuk sebagai prakonsepsi mengenai peristiiwa dan pengertian tentang konsep - konsep fisika. Akibat pencampuran konsep tersebut menjadikan penafsiran yang salah (Tayubi, 2005). Penafsiran peserta didik mengenai suatu konsep yang berbeda dengan ilmuwan fisika ini disebut dengan miskonsepsi (Fariyani, 2015). Miskonsepsi terjadi pada berbagai bidang keilmuan, salah satunya adalah fisika. Banyaknya miskonsepsi yang dialami peserta didik dalam mempelajari fisika karena banyak materi yang abstrak sehingga peserta didik sulit memahami konsep yang benar.

Saat ini terdapat berbagai penelitian yang memfokuskan kajian penelitiannya pada miskonsepsi yang tentunya akan memberikan dampak buruk dalam pembelajaran. Setiap orang dapat mengalami miskonsepsi serta miskonsepsi juga dapat terjadi pada berbagai jenjang pendidikan. Berdasarkan hasil penelitian yang pernah dilakukan sebelumnya menunjjukkan bahwa miskonsepsi yang sering terjadi dalam pembelajaran fisika yaitu pada konsep mekanika (Haris, 2016). Pada hal ini konsep dasar fisika yang sesuai dengan topik ialah mekanika dengan materi pokok Hukum Newton. Oleh karena itu, mekanika dikenal sebagai konsep yang sangat sulit dipahami materinya. Oleh karena itu, banyak peserta didik yang mengalami miskonsepsi dalam materi mekanika (Safriana \& Fatmi, 2018). Menurut pendapat Suparno (2005) secara garis besar langkah yang dipakai untuk membantu megatasi miskonsepsi adalah: 1) menemukan miskonsepsi yang dilakukan peserta didik 2) mencoba menemukan penyebab terjadiinya miskonsepsi peserta didik 3) mencari solusi perlakuan yang tepat untuk mengataasinya. Beberapa sarana diberiikan untuk menyelesaikan miskonsepsi yang tidak tepat atau tidak berhasil karena pendidik tidak dapat mengetahui persis penyebab miskonsepsi tersebut, sehingga cara yang ditempuh tidak tepat.

Miskonsepsi pada peserta didik bisa didentifikasi memakai beberapa metode salah satunya menggunakan metode Certainty of Response Index (CRI) (Hakim, 2012). Metode Certainty of Response Index (CRI) dapat mensolusi dalam mengatasi masalah yang cenderung memiliki rasa tidak yakin dengan jawaban peserta didik, metode ini juga memungkinkan peserta didik untuk mengemukakan alasan atas jawaban yang peserta didik pilih sehingga dapat mengungkapkan letak miskonsepsi peserta didik berdasarkan alasan yang peserta didik tuliskan (Hakim, 2012).

Berdasarkan uraian diatas, maka peneliti tertarik untuk mengetahui lebih lanjut pemahaman konsep peserta didik pada materi fisika dengan judul penelitian "Analisis Miskonsepsi Peserta Didik Sekolah Menengah Atas Pada Materi Fisika"

\section{METODE PENELITIAN}

CRI merupakan suatu instrumen yang baik digunakan untuk membedakan konsepsi seseoraang, apakah memiliki konsepsi yang benar, kurang pengetahuan atau terjadi miskonsepsi.

Penelitian ini memakai jenis penelitian deskriptiif analisis dengan menggunakan subjek sampel. Penelitian dilaksanakan pada peserta didik kelas X SMAN 1 DRIYOREJO. Untuk menjawab rumusan suatu masalah, yaitu dengan menghitung persentase pemahaman konsep psesrta didik, yang dapat dicari menggunakan rumus $P=f / N \times 100 \%$ (1). Kemudian acuan untuk 
menentukan kategori jawaban memakai (CRI) Certainty of Response Index (Hakim, 2012).

Tabel 1. CRI dan kriteria

\begin{tabular}{|c|c|}
\hline CRI & Kriteria \\
\hline $\mathbf{5}$ & Certain ( Sangat Paham) \\
\hline $\mathbf{4}$ & Almost Certain (Hampir \\
Paham)
\end{tabular}

Tabel 2. Ketentuan untuk membedakan antara tahu konsep, tidak tahu konsep dan miskonsepsi untuk responden secara individu.

\begin{tabular}{|l|l|l|}
\hline $\begin{array}{l}\text { Kriteria } \\
\text { Jawaban }\end{array}$ & $\begin{array}{l}\text { CRI } \\
\text { Rendah } \\
(<\mathbf{2 , 5})\end{array}$ & $\begin{array}{l}\text { CRI Tinggi } \\
\mathbf{( > 2 , 5 )}\end{array}$ \\
\hline $\begin{array}{l}\text { Jawaban } \\
\text { Benar }\end{array}$ & $\begin{array}{l}\text { Jawaban } \\
\text { benar tapi } \\
\text { CRI } \\
\text { rendah } \\
\text { berarti } \\
\text { tidak tahu } \\
\text { konsep } \\
\text { (lucky } \\
\text { guess) }\end{array}$ & $\begin{array}{l}\text { Jawaban benar } \\
\text { dan CRI tinggi } \\
\text { berarti } \\
\text { menguasai } \\
\text { konsep dengan } \\
\text { baik }\end{array}$ \\
Jawaban & Jawaban & Jawaban salah \\
\hline
\end{tabular}

\begin{tabular}{|l|l|l|}
\hline Salah & $\begin{array}{l}\text { salah dan } \\
\text { CRI rendah } \\
\text { berarti tidak } \\
\text { tahu konsep }\end{array}$ & $\begin{array}{l}\text { tapi CRI tinggi } \\
\text { berarti terjadi } \\
\text { miskonsepsi }\end{array}$ \\
\hline
\end{tabular}

Sumber: Hasan (1999)

Persamaan untuk mencari persentase peserta didik dalam menjawab soal beserta tingkat keyakinannya adalah sebagai berikut:

$\%=\frac{\text { jumlah jawaban pesert } a \text { didik }}{\text { jumlah seluruh peserta didik }} \times 100 \%(2)$

Kategori persentase dapat dikelompokkan sebagaimana pada tabel 3 berikut.

Tabel 3. Kategori Persentase

\begin{tabular}{|c|c|}
\hline Persentase & Kategori \\
\hline $0 \%-30 \%$ & Rendah \\
\hline $31 \%-61 \%$ & Sedang \\
\hline $61 \%-100 \%$ & Tinggi \\
\hline
\end{tabular}

\section{HASIL DAN PEMBAHASAN}

Berdasarkan hasil tes peserta didik menggunakan Certainty of Response Index (CRI) dengan soal berbentuk pilihan ganda, persentase pemahaman peserta didik dikelompokkan dalam kategori paham konsep dengan baik, paham konsep tetapi kurang yakin, miskonsepsi dan tidak paham konsep untuk tiap item soal sebanyak 10 item dapat dilihat pada tabel 4.

Tabel 4. Data Persentase Tingkat Pemahaman Tiap Indikator dan Item Soal

\begin{tabular}{|c|c|c|c|c|l|c|}
\hline No & Materi & $\begin{array}{c}\text { Nomer } \\
\text { Soal }\end{array}$ & $\begin{array}{c}\text { Paham } \\
\text { Konsep }\end{array}$ & $\begin{array}{c}\text { Paham } \\
\text { tetapi } \\
\text { Kurang } \\
\text { Yakin }\end{array}$ & Miskonsepsi & $\begin{array}{c}\text { Tidak } \\
\text { Paham } \\
\text { konsep }\end{array}$ \\
\hline
\end{tabular}




\begin{tabular}{|c|c|c|c|c|c|c|}
\hline \multirow{4}{*}{1} & \multirow{4}{*}{$\begin{array}{l}\text { Hukum I } \\
\text { Newton }\end{array}$} & 1 & $66,70 \%$ & $23,30 \%$ & $10,00 \%$ & $0,00 \%$ \\
\hline & & 4 & $40,00 \%$ & $20,00 \%$ & $10,00 \%$ & $30,00 \%$ \\
\hline & & 7 & $40,00 \%$ & $20,00 \%$ & $10,00 \%$ & $30,00 \%$ \\
\hline & & 8 & $33,30 \%$ & $13,30 \%$ & $30,00 \%$ & $23,30 \%$ \\
\hline \multicolumn{3}{|c|}{ Rata - rata } & $45,00 \%$ & $19,15 \%$ & $15,00 \%$ & $20,83 \%$ \\
\hline \multirow{2}{*}{2} & \multirow{2}{*}{$\begin{array}{l}\text { Hukum II } \\
\text { Newton }\end{array}$} & 2 & $10,00 \%$ & $13,30 \%$ & $50,00 \%$ & $26,70 \%$ \\
\hline & & 10 & $10,00 \%$ & $13,30 \%$ & $36,70 \%$ & $40,00 \%$ \\
\hline \multicolumn{3}{|c|}{ Rata - rata } & $10,00 \%$ & $13,30 \%$ & $43,35 \%$ & $33,35 \%$ \\
\hline \multirow{4}{*}{3} & \multirow{4}{*}{$\begin{array}{l}\text { Hukum III } \\
\text { Newton }\end{array}$} & 3 & $33,30 \%$ & $16,70 \%$ & $33,30 \%$ & $16,70 \%$ \\
\hline & & 5 & $50,00 \%$ & $10,00 \%$ & $26,70 \%$ & $13,30 \%$ \\
\hline & & 6 & $20,00 \%$ & $30,00 \%$ & $20,00 \%$ & $30,00 \%$ \\
\hline & & 9 & $33,30 \%$ & $33,30 \%$ & $23,30 \%$ & $10,00 \%$ \\
\hline \multicolumn{3}{|c|}{ Rata - rata } & $34,15 \%$ & $22,50 \%$ & $25,83 \%$ & $17,50 \%$ \\
\hline \multicolumn{3}{|c|}{$\begin{array}{c}\text { Rata - rata persentase } \\
\text { keseluruhan }\end{array}$} & $29,72 \%$ & $18,32 \%$ & $28,06 \%$ & $23,89 \%$ \\
\hline
\end{tabular}

Gambaran miskonsepsi peserta didik pada Hukum I Newton ada beberapa kasus diantaranya, pertama menjelaskan resultan gaya yang bekerja pada sebuah benda. Miskonsepsi yang terjadi ketika peserta didik menyebutkan "benda bergerak lurus berubah beraturan" termasuk Hukum I Newton, hal ini tidak benar, karena jika demikian maka tidak sesuai dengan bunyi Hukum I Newton "Jika resultan pada suatu benda sama dengan nol, maka benda yang diam akan tetap diam dan benda yang bergerak akan tetap bergerak dengan kecepatan tetap". Kedua menganalisis hubungan gaya dan gerakan benda. Miskonsepsi yang terjadi ketika ada kejadian sebuah kendaraan mengangkut barang diatas kap bergerak lalu tiba - tiba berhenti, beberapa peserta didik menyebutkan "benda di atas kap kendaraan akan tetap diam", hal itu tidak benar, karena tidak sesuai dengan penjelasan Hukum I newton bahwa sebuah benda akan mempertahankan keadaannya.

Gambaran miskonsepsi peserta didik pada Hukum II Newton ada beberapa kasus diantaranya yang paling banyak terjadi miskonsepsi saat menganalisis resultan gaya pada kecepatan sebuah benda. Miskonsepsi yang terjadi ketika peserta didik menjawab dari peristiwa benda mula-mula berjalan dengan kecepatan konstan $v 1$ kemudian dipercepat sehingga kecepatannya menjadi $v 2$ dan lebih cepat lagi menjadi v3. Jika kecepataannya beraturan, maka besar resultan gaya pada saat kecepatan becak $v 1, v 2$, dan $v 3$ adalah " $\Sigma F 1>\Sigma$ $F 2>\Sigma F 3$ ", hal ini tidak sesuai, karena hal yang 
benar adalah $\Sigma F 1=\Sigma F 2=\Sigma F 3$ sesuai dengan Hukum II Newton: $a=\frac{\sum F}{m}$

Gambaran miskonsepsii peserta didik pada5 Hukum5 III5 Newton5 ada5 beberapa5 kasus diantaranya, Menganalisis hubungan gaya yang bekerja pada kedua benda. Miskonsepsi terjadi ketika peserta didik diberikan suatu kejadian mobil melaju dengan kecepatan5tiinggi, kemudian menabrak5tiang listrik, lalu peseta didik menjawab gaya yang diberiikan mobil lebih besar daripada gaya yang diberikan tiang. Hal itu kurang sesuai, karena menurut Hukum III Newton tentang aksi-reaksi seharusnya gaya yang diberikan kedua benda sama. Adapun5 faktor-factor yang mempengaruhi miskonsepsi peserta didik tersebut adalaah 1) rendahnya minat belajar peserta didik, 2) rendahnya kemampuan peserta didik dalam memahami konsep hukum I,II,III Newton, 3) mudah menghafal namun tidak memahami makna dari Hukum Newton, 4) model pembelajaran yang diterapkan adalah model pembelajaran konvelsional, 5) kurangnya kemampuan peserta didik dalam menganalisis soal,

\section{KESIMPULAN}

Kesimpulan yang dapat dikemukakan berdasarkan hasil dari penelitian adalah faktor faktor yang menyebabkan miskonsepsi siswa kelas X SMAN 1 DRIYOREJO pada materi Fisika yaitu kemampuan peserta didik, rendahnya minat belajar peserta didik, dan cara mengajar dalam kelas yang masih konvensional. Terdapat $28,06 \%$ peserta didik yang mengalami miskonsepsi pada materi Fisika Hukum Newton.

Saran yang dapat dikemukakan adalah sebaiknya guru bidang studi dapat memberikan contoh peristiwa Hukum Newton pada kehidupan sehari - hari dan menggunakan aplikasi simulasi untuk membantu dalam mengajar materi - materi fisika agar siswa lebih memhami konsep fisika dan meningkatkan minat belajar siswa. Diharapkan kepada peneliti selanjutnya agar dapat mengembangkan instrumen dan metode tes yang digunakan.

\section{DAFTAR PUSTAKA}

Fariyani Q, et al. 2015. Pengembangan Four-Tier Diagnostic Test Untuk Mengungkap Miskonsepsi Fisika Siswa SMA Kelas X. Jurnal Universitas Negeri semarang. Vol. 4. No. 2.

Giancoli, Douglas C. 2001. Fisika Jilid 2, diterjemahkan oleh Yuhilza Hanum dari Physics Fifth Edition, Jakarta: Penerbit Erlangga.

Hakim, A. 2012. Student Concept Understanding of Natural Products Chemistry in Primary and Secondary Metabolies Using the Data Collecting Technique of Modified CRI. International Online Journal of Educational Sciences. 4 (3),544-553.

Haris, V. 2016. Identifikasi Miskonsepsi Materi Mekanika Dengan Menggunakan Cri (Certainty of Response Index). Ta'dib, 16(1). https://doi.org/10.31958/jt.v16i1.240

Hasan S, et al. 1999. Misconception and The Certainty of ResponseIndex (CRI). Physics Education. 34(5).

Mosik \& Maulana, P. (2010). Upaya Mengurangi Terjadinya Miskonsepsi Fisika Melalui Pembelajaran dengan Pendekatan Konflik Kognitif. Jurnal Pendidikan Fisika Indonesia. Vol. 6. No. 2.

Safriana. S, \& Fatmi, N. 2018. Analisis Miskonsepsi Materi Mekanika pada Mahasiswa Calon Guru Melalui Force 
Concept Inventory dan Certainty of Response Index. Jurnal Pendidikan Sains Indonesia, 6(2), 90-94. https://doi.org/10.24815/jpsi.v6i2.11897.

Suparno. 2005. Miskonsepsi dan Perubahan Konsep dalam Pendidikan Fisika. Jakarta: PT. Grasindo

Syuhendri, S. (2014). Konsepsi Alternatif Mahasiswa pada Ranah Mekanika: Analisis untuk Konsep Impetus dan Kecepatan Benda Jatuh. Jurnal Inovasi dan Pembelajaran Fisika 1 (1), 56-57

Tayubi, YR. 2005, Identifikasi Miskonsepsi pada Konsep - konsep Fisika Menggunakan Certainly of response index (CRI), Jurnal Universitas Pendidikan Indonesia, Vol. 3. No. 2. Hal. 4-9. 